\title{
Comunicação face a face nas organizações em tempos de sociedade midiatizada'
}

Face to face communication in organizations in the times of a mediatized society

Comunicación cara a cara en las organizaciones en los tiempos de sociedad mediatizada

Ana Maria Dantas de Maio

- Doutora em Comunicação Social pela Universidade Metodista de São Paulo (Umesp)

- Mestre em Comunicação pela Universidade Estadual Paulista (Unesp)

- Graduada em Jornalismo pela Universidade Estadual de Londrina (Uel)

- Jornalista do Núcleo de Comunicação Organizacional da Embrapa Pantanal desde 2007

- L Líder do projeto "Construção da imagem da pecuária sustentável do Pantanal", desenvolvido pela Embrapa entre 2010 e 2012

- Foi docente do curso de Jornalismo das Faculdades Adamantinenses Integradas (FAI)

- Membro do grupo de pesquisa Criticom-Comunicação empresarial no Brasil: uma leitura crítica, da Comtexto Comunicação e Pesquisa

- E-mail:anamaio@uol.com.br 


\section{Resumo}

Este estudo propõe reflexões sobre a comunicação face a face no contexto das organizações. Conceitua técnica e filosoficamente as interações presenciais e aquelas mediadas por tecnologias. Procura estudar as diferentes modalidades de comunicação sob a perspectiva da simultaneidade dos meios, já que atores utilizam diversos veículos para entrar em contato. Insere a comunicação face a face em diferentes correntes teóricas para avaliar sua interface com os relacionamentos, 0 planejamento da comunicação e o cenário das interações.

PALAVRAS-CHAVE: COMUNICAÇÃO FACE A FACE • COMUNICAÇÃO ORGANIZACIONAL • MIDIATIZAÇÃO • COMUNICAÇÃO MEDIADA • PANTANAL.

\section{Abstract}

This study proposes reflections on face-to-face communication in the context of the organizations. It conceptualizes technically and philosophically the physical interactions and those that are mediated by technologies. It seeks to study different types of communication under the perspective of simultaneity of the means, inasmuch as the actors resort to various vehicles to get in contact. It inserts face-to-face communication in different theoretical currents so as to evaluate its interface with relationships, communication planning and the scenario of interactions.

KEYWORDS: FACE-TO-FACE COMMUNICATION•ORGANIZATIONAL COMMUNICATION•MEDIATIZATION •MEDIATED COMMUNICATION • PANTANAL.

\section{Resumen}

Esta investigación propone reflexiones sobre la comunicación cara a cara en el contexto de las organizaciones. Conceptúa técnica y filosóficamente las interacciones presenciales y aquellas mediadas por tecnologías. Busca estudiar las distintas modalidades de comunicación bajo la perspectiva de la simultaneidad de los medios, ya que actores utilizan diversos vehículos para entrar en contacto. Insiere la comunicación cara a cara en diferentes corrientes teóricas para evaluar su interface con los relacionamientos, con el planeamiento de la comunicación y con el escenario de las interacciones. 
ANO 13 • NÚMERO 24 • 1ํSEM. 2016 - ORGANICOM

COMUNICAÇÃO FACE A FACE NAS ORGANIZAÇÕES

EM TEMPOS DE SOCIEDADE MIDIATIZADA

A comunicação face a face encontra-se afastada dos holofotes que iluminam a pesquisa em comunicação organizacional. É o que mostra levantamento feito em plataformas que reúnem pesquisas científicas no Brasil e que será detalhado na próxima seção. 0 cenário é compreensível, posto que as empresas utilizam de forma crescente as interações tecnologicamente mediadas para fazer contato com seus públicos. A presente investigação se propõe a lançar diferentes olhares sobre a inter-relação entre as duas formas de se comunicar, atentando para a diferença entre estar conectado e estar em um relacionamento.

O objetivo central do estudo é sistematizar papéis potencialmente exercidos pela interação presencial e conhecer algumas condições e particularidades que envolvem sua prática nas organizações, considerando que ela representa não apenas um dos meios possíveis de estimular relacionamentos com os públicos de interesse, mas também uma estratégia diferenciada de comunicação organizacional.

Para conhecer essas circunstâncias, foram traçados objetivos específicos: a) verificar, à luz de teorias que focalizam 0 caráter relacional da comunicação, em que medida as interações face a face interferem na construção de relacionamentos empresariais com públicos externos e internos; b) observar de que forma o acesso às manifestações do interlocutor possibilita que a organização utilize a comunicação face a face para antever reações e adaptar seu discurso; c) compreender, sob a esteira da teoria das mediações, o modo como os ambientes físicos onde ocorrem as interações face a face condiciona a comunicação organizacional, podendo inibir ou constranger o interlocutor que ocupa momentaneamente o espaço do outro.

A abordagem considerada nesta pesquisa é a da interação face a face planejada pelas empresas, por meio de programas, projetos ou políticas de comunicação. 0 estudo não contempla conversas informais. 0 interesse pelo tema surge em um momento em que a pesquisa em comunicação se volta fortemente para a compreensão do universo da comunicação digital. Paralelamente, a vivência desta pesquisadora em um ambiente tido como distante e isolado por habitantes dos grandes centros urbanos do país - a região do Pantanal brasileiro -, a levou a considerar insuficientes as conexões mediadas por tecnologias para instigar relacionamentos com alguns stakeholders.

\section{MULTIPLEXIDADE DOS MEIOS: UMA PERSPECTIVA METODOLÓGICA}

A abordagem metodológica adotada neste estudo é a da simultaneidade dos meios, ou seja, a comunicação face a face é observada a partir de sua conexão com outras formas de interação. Como a proposta é avaliar, em algumas situações, a construção e manutenção de relacionamentos ao longo do tempo, é inviável desarticular o processo comunicacional como um todo em favor de suas partes. Pessoas, grupos e organizações utilizam múltiplos meios para entrar em contato.

Essa perspectiva de multiplexidade dos meios vem sendo introduzida na pesquisa em comunicação por estudiosos norteamericanos, como Caroline Haythornthwaite (2005). Segundo ela, laços mais fortes serão estabelecidos de acordo com a quantidade de meios utilizados nas interações. Menor diversidade de meios significa, na perspectiva da autora, laços mais frágeis.

Para chegar a essa conclusão, a autora apresenta o estudo feito com um grupo de pesquisadores que trabalham fisicamente juntos. Ela chama esse estudo de Cerise. Essas pessoas se comunicam por encontros face a face casuais e programados e por diversas ferramentas tecnológicas. 
Os resultados mostraram que, condizente com as expectativas da literatura de rede social, pares em vínculos fortes (laços formais de trabalho; amigo próximo ou relacionamentos de amizade) mantêm um grande número de relações e comunicações mais frequentemente do que outros (Haythornthwaite, 2005, p. 129) ${ }^{2}$.

0 outro estudo, que a pesquisadora denomina Leep, foi feito com estudantes de um curso a distância, portanto online. Assim como o Cerise, o número de relações mantidas e a frequência da comunicação aumentaram com a proximidade do vínculo relatado. Depois de entrevistar esse público, Haythornthwaite observou os significados e a importância dos diferentes tipos de conectividades online para esses estudantes a distância, "para quem o face a face é o suplemento para sua comunidade online 'real'" (Haythornthwaite, 2005, p. 129-130)3.

Essa concepção metodológica é relevante porque os relacionamentos empresariais utilizam progressivamente instrumentos técnicos para conexões. A noção de comunicação face a face como programa, usada de forma planejada por organizações, tem sido pouco explorada cientificamente. Aliás, estudos sobre comunicação face a face, em geral, não são tão comuns.

Uma busca em plataformas de trabalhos acadêmicos e científicos permitiu localizar poucas publicações que avaliam iniciativas empresariais nessa linha - boa parte apresentando a comunicação face a face como elemento secundário. 0 levantamento foi feito em 2013 e 2014 em portais como Periódico Capes, Biblioteca Digital Brasileira de Teses e Dissertações, Google Acadêmico e bibliotecas digitais de nove universidades brasileiras.

O resultado indica a falta de estruturação do tema "comunicação face a face" no campo científico. Não há linhas de pesquisa específicas tampouco instituições que priorizem o assunto: ele se encontra difuso dentro do próprio campo da comunicação e dialoga com outras áreas do conhecimento, como turismo, gestão e desenvolvimento regional, língua portuguesa, linguística, ciência da informação e letras, demonstrando a transdisciplinaridade que caracteriza o objeto de estudo.

No universo da comunicação organizacional foram localizados alguns trabalhos que tratam dos contatos presenciais, a maioria no contexto da comunicação interna. Essa associação se explica, provavelmente, porque no âmbito interno as relações se desenvolvem em situação de copresença com mais frequência, facilitando a observação do fenômeno. Nem sempre o escopo dos estudos encontrados é a interação face a face; algumas pesquisas discutem o tema de forma transversal. Dois trabalhos relevantes localizados nesse levantamento serão analisados a seguir: as teses de doutorado de Eduardo Guerra M. Ferreira (2011) e Marta Terezinha M. C. Martins (2012), desenvolvidas, respectivamente, na Ampla, concessionária de energia do Rio de Janeiro, e na Embrapa Soja (Paraná). A comunicação face a face na Embrapa Pantanal (Mato Grosso do Sul) foi estudada de forma aprofundada em tese de doutorado que gerou o presente artigo.

\section{AS INTERAÇÕES SOCIAIS EM UM NOVO BIOS}

A compreensão do processo de midiatização da sociedade representa um passo significativo para contextualizar a relação entre a comunicação organizacional e o uso planejado da comunicação face a face. Para se comunicar com seus públicos de interesse, as organizações utilizam diferentes ferramentas tecnológicas que são introduzidas paulatinamente no ambiente social. Entretanto, o conceito de midiatização extrapola a simples adoção e intensificação do uso de meios técnicos para estabelecer contatos. 
Estudiosos de várias partes do mundo têm se debruçado sobre esse fenômeno. Para Stig Hjarvard (2012), a midiatização está diretamente relacionada à dependência que a sociedade estabelece em relação à mídia e sua lógica - o que implica considerar as relações de poder envolvendo a "instituição" mídia, outras instituições e a sociedade em geral. Trata-se de um conceito que abarca a noção de transformação social e cultural em função do uso intensivo de meios tecnológicos para a prática de interações na cotidianidade.

À medida que essa relação entre comportamento social e dependência tecnológica incide sobre a dinâmica da sociedade como um todo, as conversas presenciais são igualmente afetadas, seja no formato de seus agendamentos, na expressão e no registro de seus conteúdos e na projeção de suas continuidades. Na sociedade midiatizada, a mídia se integra a outras instituições, incluindo família, religião e trabalho, nas quais anteriormente os contatos face a face dominavam as relações. Torna-se cada vez mais comum verificar a substituição de conversas presenciais por contatos via celular ou computador, mesmo quando interlocutores ocupam a mesma cena.

Ainda segundo Hjarvard (2012), a virtualização das instituições permitiu que elas fossem acessadas do lar, o que ele chama de domesticação institucional. Esse fenômeno altera o funcionamento das relações pessoais das famílias, já que seus membros podem estar fisicamente juntos, mas mentalmente conectados a outras instituições. Essa observação é válida para outros ambientes de interação, inclusive os organizacionais.

Muniz Sodré (2002, p. 24) enfatiza que a midiatização implica "uma qualificação particular da vida, um novo modo de presença do sujeito no mundo". Daí a denominação bios midiático que o autor atribui a essa forma específica de vida, caracterizada por uma "interatividade absoluta ou conectividade permanente". 0 autor reforça que a midiatização está associada à ideia de reestruturação social e de valorização da forma dos meios de comunicação - privilegiada sobre o conteúdo.

Toda essa movimentação afeta as rotinas empresariais à medida que os relacionamentos com os públicos são construídos, mantidos ou rompidos a partir desse bios. A comunicação organizacional, que historicamente se fundamentava na perspectiva funcionalista com transmissões lineares de informação do produtor ao receptor, é induzida a se adaptar a um novo paradigma.

O que este início de século está nos ensinando é que a instabilidade deixa de ser um momento transitório para estabelecerse como um estado permanente. Portanto, os momentos de estabilidade se projetam como períodos transitórios de uma instabilidade estrutural (Manucci, 2010, p. 175).

Esse cenário impede que a comunicação seja planejada e praticada como um processo previsível. Em tempos de midiatização, as organizações passam a vislumbrar a comunicação a partir de sua dinâmica, de suas articulações e relações (Lima; Bastos, 2012). Chamado de paradigma relacional, esse novo modo de enxergar a comunicação nas organizações valoriza a figura do interlocutor, que passa a ser ouvido com mais vigor. Essa escuta envolve diversos meios e suas implicações técnicas e filosóficas.

Os contatos podem ser mediados por tecnologias, em que um artefato técnico se interpõe entre os sujeitos para driblar barreiras espaciais ou temporais. Na ausência desse objeto técnico a comunicação pode ser face a face, aquela em que os interlocutores ocupam a mesma cena e, em função disso, têm a oportunidade de observar sinais não-verbais que complementam ou contradizem o texto verbal. John B. Thompson (2008) chama esses elementos de deixas simbólicas. "Os participantes de uma interação face a face são constantemente e rotineiramente instados a comparar as várias deixas simbólicas e a usá-las para reduzir a ambiguidade e clarificar a compreensão da mensagem" (Thompson, 2008, p. 78). 
Para Alfred Schutz (1979), não basta estar frente a frente para instituir a comunicação. É necessário que os interlocutores percebam a presença do outro, identifiquem motivações e linguagem comuns, compartilhem experiências simultâneas durante determinado tempo - o que o teórico denomina de "envelhecer juntos". A atenção voltada para o tu permite que se construa o relacionamento do nós, aquele que se concretiza quando os indivíduos captam as experiências vividas pelo outro, por meio da presença corporal e dos sinais que o corpo revela da consciência alheia.

Paira ainda sobre os meios que serão utilizados na comunicação uma vasta discussão filosófica sobre os efeitos do uso exacerbado da tecnologia e da diminuição da prática do diálogo face a face. Zygmunt Bauman (2004, p. 138) apresenta uma análise crítica a respeito das interações mediadas:

Se a comunicação pudesse ser reduzida à transferência de informação, sem necessidade da "fusão de horizontes", então, em nossa era da internet e da rede mundial, o contato físico e o compartilhamento (mesmo que temporário e intermitente) de espaço e experiências teriam se tornado redundantes. Mas não se tornaram, e até agora nada indica que isso ocorrerá.

0 mesmo autor pondera que a preferência pela comunicação tecnologicamente mediada em detrimento de encontros presenciais pode acarretar prejuízos. "O que se perde é a intimidade, a profundidade e durabilidade da relação e dos laços humanos" (Bauman, 2011, p. 27). Na mesma linha, Dominique Wolton (2004, p. 35) pontua que "nenhuma técnica de comunicação, por mais eficiente que seja, jamais alcançará o nível de complexidade e de cumplicidade da comunicação humana".

Estudiosos das correntes tecnofóbicas e tecnofílicas ${ }^{5}$ divergem sobre eventuais benefícios e perdas provocados pela comunicação tecnologicamente mediada. Entre os principais argumentos daqueles que se mostram preocupados com os excessos estão a possível dificuldade de convivência com a alteridade, a superficialidade dos relacionamentos virtuais, a perda da cena comunicacional e das habilidades para desvendar as emoções alheias. Pesquisadores que enxergam no desenvolvimento tecnológico a solução para as grandes dificuldades de relacionamento sugerem que 0 outro grupo é formado por mentes conservadoras.

\section{DA METACOMUNICAÇÃO AO ESPAÇO FÍSICO}

Este estudo procura visualizar a comunicação face a face sob diferentes perspectivas e constrói três linhas de investigação envolvendo sua prática. A primeira se sustenta na corrente teórica que explora a metacomunicação, isto é, a comunicação mais preocupada com os relacionamentos que se criam por meio de diálogos do que com a circulação de conteúdo. Pesquisadores ligados à Escola de Palo Alto defendem que a comunicação tem o poder de definir a relação, ou seja, ela não apenas transmite um conteúdo (relato) como impõe um comportamento (ordem). Na prática, na visão desse grupo, comunicação e relacionamento se sobrepõem.

Ainda na esteira dessa corrente teórica, além das instâncias de poder que envolvem os relacionamentos, ao menos outros dois fatores condicionam os diálogos: as manifestações não-verbais expressas durante o contato e a circunstância em que a comunicação ocorre. Esse grupo de estudiosos sustenta que o contexto sempre restringe a comunicação, em maior ou menor grau, e inclui nesse caráter limitante a própria troca de conteúdos. "Numa sequência comunicacional, toda e qualquer troca de mensagens restringe o número dos possíveis movimentos seguintes"(Watzlawick; Beavin; Jackson, 2007, p. 120. Grifo dos autores).

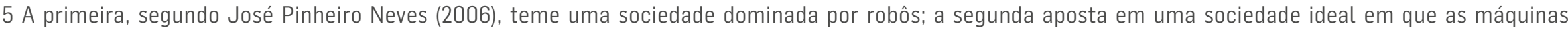
permitem uma vida feliz. 
Entender a relação entre comunicação e relacionamento permite averiguar se as interações face a face contribuem para que as organizações construam e aprimorem suas relações com públicos de interesse - quando adotadas de forma planejada. Algumas empresas têm implantado projetos e políticas de comunicação que preveem contatos face a face justamente na tentativa de incrementar relacionamentos. É o caso da Ampla, do Rio de Janeiro, e das unidades Soja e Pantanal da Embrapa, no Paraná e Mato Grosso do Sul, respectivamente.

Para Martins (2012), que estudou o uso estratégico da oralidade na comunicação interna da Embrapa Soja, em Londrina (PR), "comunicação é relacionamento humano e implica considerá-la fator presente entre os indicadores para que a sociedade de hoje consiga coexistir com as organizações" (Martins, 2012, p. 65). Mais do que uma opção de meio de comunicação, a autora enxerga a oralidade como uma orientação de sua política de relacionamentos.

0 mesmo estudo aponta que a comunicação oral na Embrapa Soja promove mudanças de comportamento nas partes envolvidas: os chefes da organização passam a conhecer as expectativas dos subordinados; por outro lado,

o valor do diálogo e das interações foi marcante nas inferências dos empregados que declararam apreciar exposição oral de seu líder imediato, pois confirmaram que a comunicação face a face era uma forma de interação que permitia adequações imediatas às necessidades, à linguagem e às condiç̃̃es do interlocutor (Martins, 2012, p. 222).

A Ampla Energia e Serviços S.A. instituiu um programa de diálogo social (face a face) para se aproximar da comunidade vizinha e, da mesma forma que a Embrapa Soja, conseguiu mudanças de comportamento. Uma das conclusões do estudo de Ferreira (2011) sobre a concessionária é que a prática da comunicação face a face provocou mudanças significativas tanto na empresa como na comunidade. A Ampla encarou um processo de abertura e conseguiu incorporar aspectos da cultura externa, enquanto a comunidade vizinha passou a estabelecer expectativas e exigências diferenciadas em relação aos agentes produtivos locais.

A Embrapa Pantanal desenvolveu um projeto de comunicação que privilegiou as interações cara a cara para criar relacionamentos com públicos externos, especificamente jornalistas de redações instaladas na região Sudeste do Brasil. Os contatos iniciais, que aconteceram tanto nas capitais como em fazendas do Pantanal, foram fundamentais, na perspectiva da organização, para que uma relação de confiança entre os agentes fosse criada e os diálogos tivessem continuidade nos anos seguintes. Todas essas experiências, cientificamente averiguadas, revelam a viabilidade da metacomunicação.

Uma segunda perspectiva de investigação indica que a interação face a face proporciona a observação direta das reações dos interlocutores; com isso, a organização que utiliza essa modalidade de comunicação de forma planejada obtém acesso a elementos não-verbais que permitem prever essas reações e ajustar sua conduta e seu discurso. A fundamentação teórica dessa premissa provém de George Mead, considerado o precursor do interacionismo simbólico.

Mead (1973) propõe um deslocamento do sujeito, ou seja, que os indivíduos em interação procurem se colocar no lugar do outro na tentativa de prever suas reações - com base em processos de construção de significados. A mesma lógica de antecipação do comportamento da alteridade e eventuais ajustes prévios é encontrada em pesquisas desenvolvidas por Alfred Schutz (1979), John Thompson (2011), Erving Goffman (2011) e José Luiz Braga (2012), que contribuem para a discussão teórica a respeito do tema.

Estudos acadêmicos avaliam a ocorrência desse fenômeno na prática da comunicação organizacional. Um chefe da Embrapa Soja (identificado como Sujeito A), entrevistado por Martins (2012), evidencia que, por meio da comunicação face a face, é 
possível observar características específicas de cada interlocutor, o que permite a personalização de cada discurso. Os ajustes se processam no decorrer da interação:

Com uma conversaolhono olho agente pode verqual a reação do indivíduo, a gente pode utilizar a conversa de repente para motivar, para trocar o foco, de repente conforme o cara tá olhando você percebe que não tá agradando, eu acho que é importantíssima comunicação boca a boca, olho a olho, pequenos grupos, é muito bom, porque a gente age conforme o cara vai reagindo (Sujeito A, apud Martins, 2012, p. 174).

Na Ampla, também foi observada essa ocorrência. "Cabe a uma organização, que deseje desenvolver espaços profícuos de interação, ser capaz de 'assumir o papel' dos atores sociais com os quais irá interatuar para relativizar sua posição e buscar um consenso" (Ferreira, 2011, p. 166). Em Corumbá (MS), a experiência registrada na Embrapa Pantanal reforça essa perspectiva. Encontros face a face entre sujeitos ligados a essa organização e alguns stakeholders permitiram inferir que o planejamento da comunicação organizacional pode ser favorecido pelo acesso às chamadas deixas simbólicas, seguida por devidas interpretações e ressignificações. Reações desfavoráveis de um determinado público puderam ser percebidas durante o contato físico e indicaram a necessidade de mudanças imediatas ou a médio e longo prazo.

A terceira abordagem da comunicação face a face proposta por este estudo se traduz na análise contextual dos diálogos, mais precisamente no elemento "espaço físico". A ideia é averiguar se o território onde se desenvolve a interação face a face interfere na comunicação organizacional, provocando constrangimento nos interlocutores que venham a ocupar temporariamente o espaço dominado pelo outro.

Essa discussão tem como suporte teórico-metodológico a controversa teoria das mediações sociais. 0 espanhol Manuel Martín Serrano começa a esboçar a teoria da mediação social no final da década de 1970, definindo mediação como "a atividade de controle social que impõe limites ao que poderia ser dito, e às maneiras de dizê-lo, por meio de um sistema de ordem" (Martin Serrano, 1976, p. 180) ${ }^{6}$.

Essa forma de controle consistiria do domínio dos códigos de interpretação disponibilizados pelo meio de comunicação, no caso específico estudado por ele, a televisão. 0 pesquisador defende que o controle social exercido por essa mídia ocorre menos em função da diversidade de conteúdo que ela oferece à audiência e mais pela restrição de códigos de interpretação transmitidos por meio das mensagens.

Quando outros autores latino-americanos começam a aprofundar esses estudos, a ideia de mediação social se converte em mediações sociais, no plural, pois várias são as instâncias capazes de intervir na interpretação/recepção de mensagens. Jesús Martín-Barbero (2000, p. 154) aponta:

O que eu comecei a chamar de mediações eram aqueles espaços, aquelas formas de comunicação que estavam entre a pessoa que ouvia o rádio e o que era dito no rádio. (...) Mediação significava que entre estímulo e resposta há um espesso espaço de crenças, costumes, sonhos, medos, tudo o que configura a cultura cotidiana.

Essa concepção original da teoria das mediações foi se atualizando. 0 próprio Martín-Barbero reconhece a necessidade de deslocar suas pesquisas das mediações culturais da comunicação para as mediações comunicativas da cultura. Essa migração acontece porque o teórico percebe a força com que os meios de comunicação incidem sobre a sociabilidade. Apesar das críticas que a concepção barberiana vem recebendo, em função de sua inconsistência metodológica, seu envelhecimento e seu abstracionismo, observa-se que essa corrente é capaz de explicar o mecanismo de funcionamento de eventual constrangimento ou outros efeitos restritivos proporcionados por instâncias mediadoras.

6 Tradução nossa. 
O espaço geográfico é entendido aqui como a área física, mensurável, natural ou artificial, que serve como cenário para as interações sociais, e não será considerado uma mediação em si. Para a análise aqui empreendida, será levado em conta o papel mediador dos lugares geográficos, ou seja, as formas como esses locais condicionam a construção de sentidos durante o processo de interação face a face.

Para autores da geografia, as interações de pessoas com o ambiente são fundamentais para a compreensão do que chamam de paisagens - urbanas ou rurais. "O sentido da paisagem não pode ser dado apenas pelo universo teórico e existencial do observador, sob o risco de um estereótipo. Na verdade, a paisagem é mais intensamente revelada a partir das pessoas que têm nela uma experiência comum", diz Euler Sandeville Junior (2004, p. 3).

Goffman (2011) acrescenta elementos essenciais para essa discussão, como o controle do cenário onde ocorre o encontro e o nível de transparência que se pretende exibir. Ao avaliar as representações de fachada (ações que se quer mostrar) e de fundo (comportamentos de bastidores), o autor explica que o domínio do cenário pode propiciar à equipe responsável uma sensação de segurança, pois cabe a ela a condução do processo. Por outro lado, esse comando representa um risco de exposição dos bastidores, na concepção do autor.

Certamente é preciso pagar um preço pelo privilégio de realizar uma representação na própria casa; a pessoa tem a oportunidade de transmitir informações a seu próprio respeito por meios cênicos, mas nenhuma oportunidade de esconder as espécies de fatos transmitidos pelo cenário (Goffman, 2011, p. 92).

Em função dessa vulnerabilidade, a pesquisa detecta que a ocorrência de constrangimento pode afetar não apenas os visitantes, mas também os anfitriões. A definição de constrangimento vem da psicologia social e indica um estado emocional ligado à ansiedade gerada em função do reconhecimento da expectativa alheia durante uma situação de interação real ou imaginária.

0 controle do cenário onde ocorrem as interações face a face - e a associação de possíveis constrangimentos ao território - representa uma das instâncias que incidem sobre o papel mediador do espaço físico, mas não a única. 0 ambiente vai determinar, muitas vezes, o assunto sobre o qual se fala. É bastante provável, por exemplo, que, ao se deslocarem para lugares como a Floresta Amazônica e o Pantanal, anfitriões e visitantes sejam induzidos a conversar sobre os animais, a vegetação, o clima, a devastação e outros temas relacionados. 0 repertório cultural dos atores é outro indicador que incide sobre os assuntos em determinado local.

O fato é que os territórios, por si, não podem ser considerados uma mediação social. 0 que os transforma em instância mediadora é a composição entre a área física e as regras sociais previstas para seu uso e ocupação. Os estudos organizacionais desenvolvidos na Embrapa Soja e na Ampla indicam que alguns espaços induzem a certos comportamentos. Chefes da primeira empresa evitam chamar seus subordinados para algumas conversas em suas salas. Preferem se dirigir ao ambiente de trabalho do empregado para evitar constrangimentos (Martins, 2012) - o trabalho não menciona a possibilidade de que ser chamado à sala do chefe possa representar uma situação de prestígio e valorização do funcionário.

A vizinhança da Ampla, chamada a dialogar com a organização, manifesta o desejo de que as conversas pudessem ocorrer fora do território da empresa, em um espaço na comunidade (Ferreira, 2011). Nesses e em outros casos subentende-se que o local dos diálogos traz consigo pressuposições que podem estar associadas ao poder e à hierarquia, limitando 0 potencial da comunicação face a face. 
Outros cenários, como o Pantanal, aparentam ser mais favoráveis ao fluxo contínuo de diálogos. Se a vista panorâmica transmite a sensação de imutabilidade, no Pantanal ela também se associa à infinitude ou ausência de limites. Afora a percepção da distância e da extensão do bioma, o simples fato de viver naquele espaço parece imprimir determinadas características aos habitantes:

Embora cada ambiente ou ecossistema possa afetar as pessoas de forma distinta, há, provavelmente, um efeito geral que provoca praticamente as mesmas reações em todos os frequentadores. Quem passa muito tempo no mar, por exemplo, se expõe mais a determinados sentimentos - e a maioria das pessoas sente exatamente esses mesmos "determinados sentimentos"; quem mora no Pantanal tende a falar manso, ser desconfiado e, ao mesmo tempo, solidário; 0 sujeito que vive na floresta amazônica tem uma índole diferente daquele que vive na mata atlântica (Moraes, 2014)?

Dessa maneira, observa-se que os espaços físicos - associados às regras sociais previstas para sua ocupação (códigos) podem, sim, condicionar algumas situações de comunicação face a face, atuando como instância mediadora dos diálogos. 0 comunicador organizacional que atua em espaços considerados peculiares, como Pantanal e Amazônia, precisa conhecer esses códigos bem como o nível de intervenção do processo de midiatização nesses ambientes.

\section{CONSIDERAÇÕES FINAIS}

Embora a prática estratégica da comunicação face a face nas organizações se encontre aquém de sua potencialidade, este estudo demonstra que algumas empresas estão adotando essa modalidade de forma planejada e com resultados positivos. Ficou delineado que as interações face a face no ambiente organizacional são capazes de construir e manter relacionamentos sólidos e de qualidade, bem como aperfeiçoar o processo de comunicação organizacional a partir da observação das reações alheias e ajustes de conduta dos interlocutores.

O estudo explora elementos contextuais que condicionam a comunicação face a face, especialmente o espaço físico. Foram identificadas algumas instâncias mediadoras presentes nos cenários e que interferem na forma como as conversas são construídas ou interrompidas. 0 conhecimento sobre o espaço físico envolve a interdisciplinaridade - recorreu-se a ciências como geografia e sociologia para compreender como se dá esse condicionamento.

A controversa teoria das mediações sociais foi resgatada para a compreensão desse fenômeno. Na atualidade, esse estudo se encontra imbricado nas investigações a respeito da midiatização da sociedade. A pesquisa permite inferir que o processo de midiatização - embora aparentemente irreversível - deve ser relativizado. Mudanças na dinâmica social avançam em ritmos diversos dependendo do território e da cultura herdada por seus habitantes.

\section{REFERÊNCIAS}

BAUMAN, Zygmunt. Amor líquido: sobre a fragilidade dos laços humanos. Rio de Janeiro: Zahar, 2004. 44 cartas do mundo líquido moderno. Rio de Janeiro: Zahar, 2011.

7 As contribuições do socioeconomista André Steffens Moraes, ex-pesquisador da Embrapa Pantanal, ex-marujo e atual pesquisador da Embrapa Soja, foram incorporadas a esse estudo pela perspicácia de suas impressões pessoais sobre a paisagem pantaneira, elaboradas ao longo dos anos em que frequentou aquele ecossistema. 
BRAGA, José Luiz. La política de los internautas es producir circuitos. In: CARLÓN, Mario; FAUSTO NETO, Antonio (orgs.). Las políticas de los internautas. nuevas formas de participación. Buenos Aires: La Crujía, 2012. p. 43-59 [ou 1-14 na cópia em português cedida pelo autor].

FERREIRA, Eduardo Guerra Murad. Diálogo social: a comunicação na construção dos relacionamentos das organizações com as comunidades vizinhas: o caso Ampla. 2011. Tese (Doutorado em Ciência da Comunicação) - Escola de Comunicação e Artes, Universidade de São Paulo, São Paulo, 2011.

GOFFMAN, Erving. A representação do eu na vida cotidiana. 18. ed. Trad. de Maria Célia Santos Raposo. Petrópolis, RJ: Vozes, 2011.

HAYTHORNTHWAITE, Caroline. Social networks and internet connectivity effects. Information, Communication \& Society, Abingdon, v. 8, n. 2, p. 125-147, jun. 2005.

HJARVARD, Stig. Midiatização: teorizando a mídia como agente de mudança social e cultural. Matrizes, São Paulo, a. 5, n. 2, p. 5391, jan./jun. 2012. Disponível em: <http://www. matrizes.usp.br/index.php/matrizes/article/view/338/pdf>. Acesso em: 21 abr. 2015.

LIMA, Fábia Pereira; BASTOS, Fernanda de Oliveira Silva. Reflexões sobre o objeto da comunicação no contexto organizacional. In: OLIVEIRA, Ivone de Lourdes; LIMA, Fábia Pereira (orgs.). Propostas conceituais para a comunicação no contexto organizacional. São Caetano do Sul, SP: Difusão; Rio de Janeiro: Senac Rio, 2012. p. 25-48.

MAIO, Ana Maria Dantas de. O papel da comunicação face a face nas organizações no contexto da sociedade midiatizada. 2016. Tese (Doutorado em Comunicação Social) - Universidade Metodista de São Paulo, 2016.

MANUCCI, Marcelo. Otreinamento das organizações para as contingências em um novo contexto da comunicação corporativa. In: KUNSCH, Margarida Maria Krohling (org.). A comunicação como fator de humanização das organizações. São Caetano do Sul, SP: Difusão, 2010. p. 171-183.

MARTÍN SERRANO, Manuel: mediación. In: DEL CAMPO, Salustiano (org.). Diccionario de ciencias sociales. Madrid: Instituto de Estudios Políticos/Unesco, p. 179-184, 1976. Disponível em: <http://eprints.ucm.es/10657/>. Acesso em: 3 ago. 2014.

MARTíN-BARBERO, Jesús. Comunicação e mediações culturais. Entrevistador: Claudia Barcelos. Revista Brasileira de Ciências da Comunicação, São Paulo, v. 23, n. 1, p. 151-163, jan./jun. 2000. Disponível em: <http://www.portcom.intercom. org.br/ revistas/index.php/revistaintercom/article/view/541/510>. Acesso em: 26 nov. 2013.

MARTINS, Marta Terezinha Motta Campos. Diálogo e interações face a face na comunicação interna: um estudo da oralidade nas organizações. 2012. Tese (Doutorado em Ciências da Comunicação) - Escola de Comunicação e Artes, Universidade de São Paulo, São Paulo, 2012.

MEAD, George H. Espiritu, persona y sociedad: desde el punto de vista del conductivismo social. Barcelona: Paidós Ibérica, 1973.

MORAES, André Steffens. Percepções sobre a paisagem no Pantanal. [Mensagem pessoal]. Mensagem recebida por ana. maio@embrapa.brem 11 fev. 2014.

NEVES, José Pinheiro. 0 apelo do objecto técnico. Porto, Portugal: Campo das Letras, 2006.

SANDEVILLE JUNIOR, Euler. Paisagens e métodos: algumas contribuições para elaboração de roteiros de estudo da paisagem intraurbana. Paisagens em debate, São Paulo, n. 2, p. 1-6, set. 2004. Disponível em: <http://www.usp.br/fau/depprojeto/ gdpa/paisagens/inicio.html>. Acesso em 23 jun. 2015. 
SCHUTZ, Alfred. 0 mundo das relações sociais. In: WAGNER, Helmut R. (org.). Fenomenologia e relações sociais: textos escolhidos de Alfred Schutz. Rio de Janeiro: Zahar Editores, 1979. p. 157-237. Disponível em: <https://www.passeidireto. com/arquivo/2295273/alfred-schutz---fenomenologia-e-relacoes-sociais-livro>. Acesso em: 27 nov. 2014.

SODRÉ, Muniz. Antropológica do espelho: uma teoria da comunicação linear e em rede. Petrópolis, RJ: Vozes, 2002.

THOMPSON, John B. A mídia e a modernidade: uma teoria social da mídia. 9. ed. Petrópolis, RJ: Vozes, 2008.

Ideologia e cultura moderna: teoria social crítica na era dos meios de comunicação de massa. 9. ed. Petrópolis: Vozes, 2011.

WATZLAWICK, Paul; BEAVIN, Janet Helmick; JACKSON, Don D. Pragmática da comunicação humana: um estudo dos padrões, patologias e paradoxos da interação. São Paulo: Cultrix, 2007.

WOLTON, Dominique. Pensar a comunicação. Brasília: Editora Universidade de Brasília, 2004.

Artigo recebido em 12.05.2016 e aprovado em 18.06.2016. 